\title{
ASSESSMENT OF LYMPHOCELE INCIDENCE FOLLOWING 450 RENAL TRANSPLANTATIONS
}

\author{
VICTOR T. DUBEAUX, RENÉ M. OLIVEIRA, VICTOR J. MOURA, J. MONTEIRO S. \\ PEREIRA, FABIO P. HENRIQUES \\ Section of Urology, Clementino Fraga Filho University Hospital, Federal University of Rio de Janeiro, Rio \\ de Janeiro, RJ, Brazil
}

\begin{abstract}
Objective: To determine the incidence of lymphocele in the follow-up of patients who underwent renal transplantation, as well as potential factors responsible or associated to its development.

Materials and Methods: All records from patients who were treated for lymphocele in our institution between May 1989 and December 2002 were reviewed, as well as their clinical outcome following treatment.

Results: Among 450 patients who underwent renal transplantation in the period, only 3 required treatment, with 2 of them treated due to the collection volume, and the other due to symptoms (pain), representing an incidence of only $0.6 \%$.

Comments: The occurrence of perirenal fluid collections following renal transplantation is frequent. In cases where treatment is required, this can generate an excessive morbidity for the patient, which motivates the development of preventive methods, such as minimally invasive therapy, for such cases.

Conclusion: Careful ligation of lymphatic vessels both during graft preparation and during its implantation, added to post-operative drainage can significantly contribute to reducing the incidence of lymphocele following renal transplantation.
\end{abstract}

Key words: renal transplantation; lymphocele; prevalence; predisposing factors; surgical procedures, operative

Int Braz J Urol. 2004; 30: 18-21

\section{INTRODUCTION}

Lymphoceles are the fluid collections most frequently found following renal transplantation, occurring in up to $22 \%$ of transplantations performed in the United States every year (1). The risk of developing a lymphocele is associated to previous episode of acute rejection, incomplete ligation of lymphatic vessels in the graft, high doses of steroids and extensive perivascular dissection in the recipient, among other causes (1).
The majority of cases develops during the first year following surgery, and is asymptomatic, with no need of treatment (2). However, symptomatic cases can evolve with increase in creatinine levels and a fall in the urinary output due to the compression exerted over the implanted kidney or ureter. It can manifest as a palpable mass, with abdominal pain, or edema in lower limbs due to the compression of the iliac vessels (3).

Therapeutic options include percutaneous drainage, aspiration followed by infusion of a scle- 
rosing agent, or internal (peritoneal) drainage, by both laparoscopic and open surgery $(4,5)$.

The objective of this work was to determine the incidence of lymphocele in the follow-up of patients who underwent renal transplantation, as well as potential factors that could be responsible or associated to its development.

\section{MATERIALS AND METHODS}

After reviewing the records of patients who underwent surgical intervention for treatment of lymphocele between May 1989 and December 2002, we investigated its incidence, and the treatment performed.

Patients' age ranged from 27 to 45 years, with all of them being Caucasian and male.

Patients received an immunosuppressive regimen that consisted of cyclosporine, fk 506 (tacrolimus), corticotherapy, mycofenolate mofetil and rapamicine, at the discretion of our nephrologic team.

\section{RESULTS}

Among the 450 patients who were transplanted until then, only $3(0.6 \%)$ presented a clinical picture of lymphocele requiring intervention post-operatively. One case was symptomatic and the other 2 were incidentally diagnosed through ultrasonography scans.

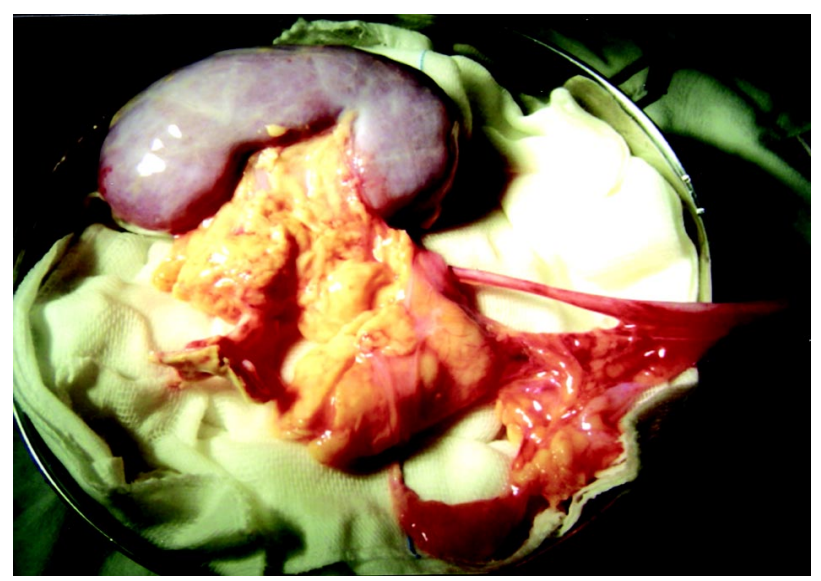

Figure 1 - Kidney from cadaveric donor. Note the preservation of periureteral fat and its vascularization, in spite of ischemia.
One patient who presented a symptomatic lymphocele measuring $20 \times 15 \mathrm{~cm}$ on the ultrasound underwent intervention, as well as the other 2 who had voluminous collections, even if asymptomatic, due to the volume detected by ultrasonography $(10 \mathrm{x}$ $8 \mathrm{~cm}$ and $15 \times 12 \mathrm{~cm}$ ), and the suspected possibility of occurrence of subsequent infection.

Resolution was achieved by percutaneous drainage in 2 cases. The third patient presented recurrence following drainage and underwent surgical treatment with drainage of the collection to the peritoneum by conventional approach, and did not present recurrence in the post-operative period.

The collected material was submitted to biochemical and microbiological analysis, revealing to be sterile and presenting biochemical characteristics of lymph.

All patients were recipients of kidneys from cadaveric donors, and had their implants prepared by the same team, with rigorous ligation of lymphatic vessels, including the ureteral ones (Figures1 and 2). The implantation was performed in the right iliac fossa in 2 cases and in the left fossa in 1 case, followed by open drainage of the cavity for 48 to 72 hours, according to the output present postoperatively. The ureteroneocystostomy was performed using the extravesical technique (LichGregoire) in all cases, without placement of doubleJ stent.

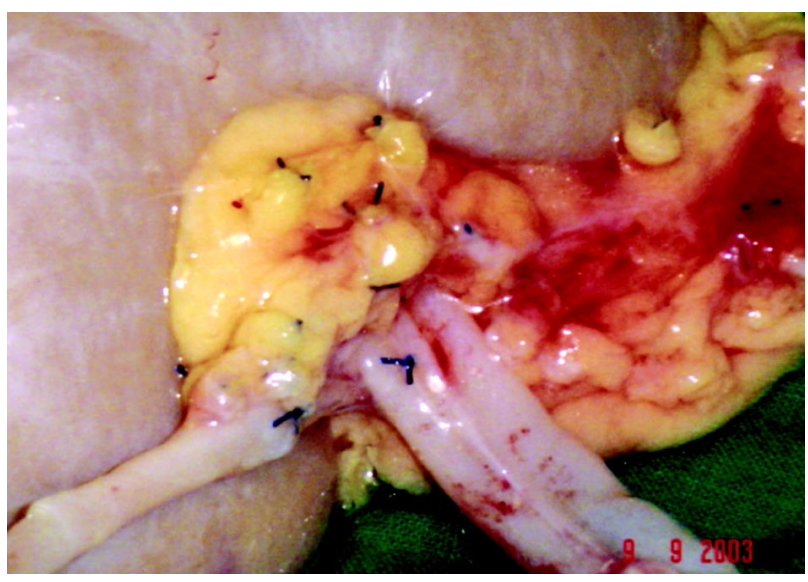

Figure 2 - Ligation of perihilar lymphatic vessels. Note the ligation of the vessel in the renal vein, and the renal artery above. 
The arterial anastomoses were performed in the internal iliac artery (termino-terminal) and common iliac vein (termino-lateral).

Patients were follow-up for an average of 6 months (between 4 and 8 months) without recurrence and with no need of further treatment.

\section{DISCUSSION}

The development of lymphoceles following renal transplantation is a reality that urologists who develop such activity must live with. The use of ultrasonography increased the index of detection for these fluid collections, though the majority of them have small size, and resolved spontaneously (2). While the etiopathogeny of its formation remains unclear, many risk factors for its development have already been postulated. It is believe that extensive perivascular dissection along the route of iliac vessels, episodes of acute rejection, cadaveric versus live donors, high doses of corticotherapy, re-transplantation, and polycystic disease in the recipients, are factors that contribute to the development of fluid collections. Nevertheless, little has been done to prevent the occurrence of lymphocele, besides preventing acute rejection $(1,5)$.

We believe that the low incidence of lymphoceles in this patient series results from the careful ligation of lymphatic vessels in the graft, extending from the renal hilum and along the ureter, which is not dissected, thus preventing a decrease in its vascularization. Moreover, the recipient's lymphatic vessels are also carefully ligated along the area where the vascular anastomoses will be subsequently performed.

Additionally, open drainage of the graft cavity, routinely performed in the post-operative period, until a decreased in output, can also account for the low indexes of collection detected in the late post-operative period, since the transudation is very high during the first 24 to $48 \mathrm{~h}$ following surgery. Though many works report such measure to be unnecessary, since the lymphatic dissection and ligation are carefully performed, we believe that such procedure adds low morbidity and contributes for the low rates of lymphocele.
An interesting fact detected in this review was that all cases occurred after 1996, when the immunosuppressive regimens were practically the same used nowadays, and our team had already been trained for performing such procedure.

\section{CONCLUSION}

Lymphoceles are common complications following renal transplantation, and can lead to an increase in morbidity for this procedure. The use of a standardized dissection technique with rigorous ligation of the lymphatic vessels in the graft and drainage of the cavity can prevent or decrease its occurrence, regardless of the presence of predisposing factors to its formation. However, prospective randomized studies are required to establish the real need of this meticulous procedure during the organ preparation and the dissection in the surgical field.

\section{REFERENCES}

1 Khauli RB, Stoff JS, Lovewell T, Ghavamian R, Baker $S$ : Post transplant lymphoceles: a critical look into the risk factors, pathophysiology and management. J Urol. 1993; 150: 22-6.

2 Pollak R, Veremis SA, Maddux MS, Mozes MF: The natural history of and therapy for perirenal fluid collections following renal transplantation. J Urol. 1988; 140: 716-20.

3 Chin A, Ragavendra N, Hilborne L, Gritsch HA: Fibrin sealant sclerotherapy for treatment of lymphoceles following renal transplantation. J Urol. 2003; 170: 380-3.

4 Shaver TR, Swanson SJ 3rd, Fernandez-Bueno C, Kocandrle V: The optimal treatment of lymphoceles following renal transplantation. Transpl Int. 1993; 6: 108-10.

5 Fahlenkamp D, Raatz D, Schonberger B, Loening SA: Laparoscopic lymphocele drainage after renal transplantation. J Urol. 1993; 150: 316-8.

6 Sansalone CV, Aseni P, Minetti E, Di Benedetto F, Rosseti O, Manoochehri F, et al.: Is lymphocele in renal transplantation an avoidable complication? Am J Surg. 2000; 179: 182-5.

7 Huilgol AK, Sundar S, Karunagaran SG, Sudhakar S, Sreenivasa Pr MA, Ravindran T: Lymphoceles and their management in renal transplantation. Transplant Proc. 2003; 35: 323. 
8 Chandrasekaran D, Meyyappan RM, Rajaraman T: Instillation of povidone to treat and prevent lymphocele after renal transplantation. BJU Int. 2003; 91: 296.
9 Fuller TF, Kang SM, Hirose R, Feng S, Stock PG, Freise $\mathrm{CE}$ : Management of lymphoceles after renal transplantation: laparoscopic versus open drainage. J Urol. 2003; 169: 2022-5.

Received: October 20, 2003 Accepted after revision: February 16, 2004

Correspondence address:

Dr. Victor T. Dubeaux

Est da Gávea, 611, bl. 1, 403

Rio de Janeiro, RJ, 22610-000, Brazil

E-mail: vdubeaux@bol.com.br 